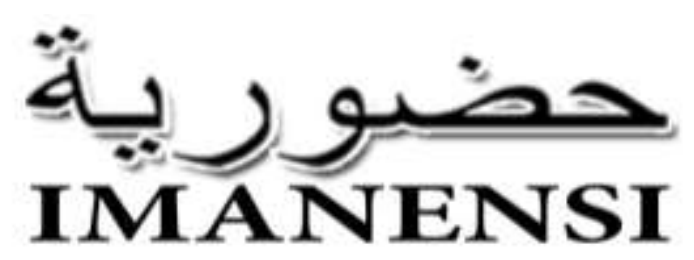

Jurnal Ekonomi, Manajemen, dan Akuntansi Islam

Vol 5, No 1, Maret 2020, Hlmn. 17-24

\title{
Circle bottom line: mengkonstruksi akuntansi sosial lingkungan dalam bingkai spiritualitas
}

\author{
Febrina Nur Ramadhani a,1,* \\ Dessy Ekaviana b,
}

aUniversitas Brawijaya, Jl. Mayjen Haryono 169 Malang, Indonesia 65145 1febrina.nr94@gmail.com*

* penulis koresponden

doi) 10.34202/imanensi.5.1.2020.17-24.

\begin{abstract}
Abstrak
Tulisan ini mencoba untuk menyempurnakan konsep triple bottem line dengan menyusun kembali relasi antara dimensi triple $P$ dan spiritualitas, yang kemudian dinamakan circle bottom line. Circle bottom line mencakup tiga dimensi yakni people (sosial), planet (lingkungan), profit (ekonomi) yang dilandasi dimensi spiritualitas dalam pengukurannya. Dimensi spiritualitas yang digunakan yakni spirit religius. Dalam hal ini adalah konsep Eco-Theology Islam yang mencakup tiga prinsip, yakni tawhìd (kesatuan seluruh makhluk), amānah-khalifah (kejujurankepemimpinan), dan äkhirah (tanggung jawab). Relasi antar dimensi circle bottom line yang berbasis prinsip-prinsip Islam pada Eco-Theology Islam kemudian dijadikan sebagai dasar penerapan akuntansi sosial-lingkungan.
\end{abstract}

Kata Kunci: Akuntansi Sosial-Lingkungan; Circle Bottom Line; Eco-Theology Islam.

\begin{abstract}
This paper tries to refine triple bottem line concept by rearranging the relations between triple $P$ dimensions and spirituality, which is then called circle bottom line. Circle bottom line includes three dimensions, namely people (social), planet (environment), profit (economy) based on the dimensions of spirituality in measurement. The dimension of spirituality used is religious spirit. In this case the concept of Eco-Theology of Islam includes three principles, namely tawhìd (unity of all beings), amānah-khaliffah (honesty-leadership), and äkhirah (responsibility). The inter-dimensional relationship of circle bottom line based on Islamic principles in the Eco-Theology of Islam is then used as the basis for the application of socialenvironmental accounting.
\end{abstract}

Keywords: Socio-Environmental Accounting; Circle Bottom Line; Eco-Theology of Islam.

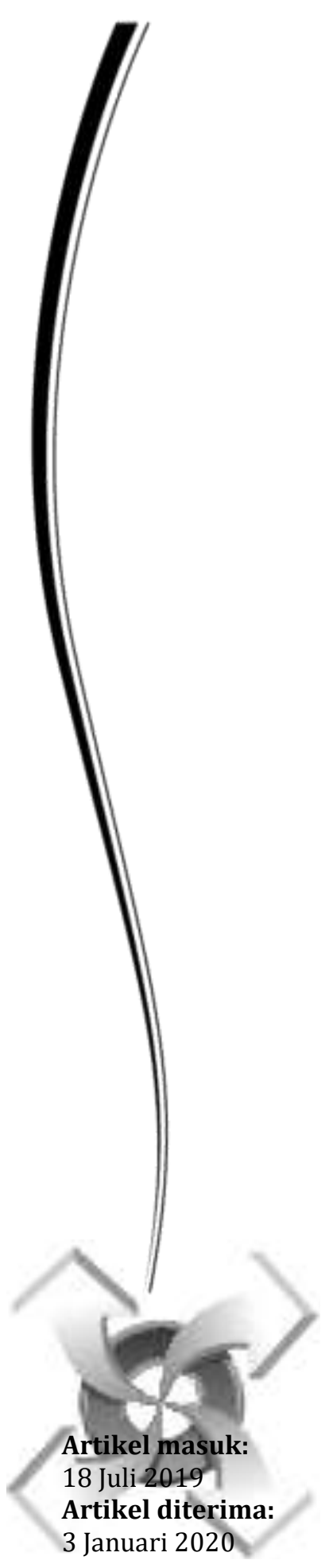

This is an open access article under the CC-BY-SA license. 


\section{PENDAHULUAN}

Gray, Owen, \& Adams (1996), mendefinisikan akuntansi sosiallingkungan sebagai akuntansi untuk berbagai peristiwa sosial dan lingkungan, bukan hanya akuntansi untuk peristiwa ekonomi. Lebih lanjut, Bebbington, Brown, Frame, \& Thomson (2007), berpendapat bahwa, akuntansi sosial-lingkungan merupakan bidang akuntansi yang bersifat inklusif untuk peristiwa sosial dan lingkungan yang timbul sebagai akibat dari tindakan ekonomi organisasi. Berdasarkan beberapa pengertian tersebut dapat dismpulkan bahwa akuntansi sosial-lingkungan adalah proses mengkomunikasikan dampak sosial dan lingkungan dari tindakan ekonomi organisasi tertentu. Dengan demikian, hal tersebut melibatkan perluasan akuntabilitas organisasi (khususnya korporasi). Perluasan tersebut didasarkan pada asumsi bahwa perusahaan memiliki tanggung jawab yang lebih luas daripada hanya menghasilkan keuntungan bagi pemegang saham.

Fenomen munculnya akuntansi sosial juga membuat banyak peneliti yang melakukan penelitian tentang akuntansi sosial-lingkungan. Dimulai dari kemunculan enterprise theory yang digagas oleh John Elkington tahun 1997. Teori ini memunculkan konsep akuntansi sosial dan lingkungan yang merupakan perluasan dari konsep ecomonic bottom line yang memandang akuntansi hanya terbatas pada aspek keuangan saja dan dikenal dengan istilah triple bottom line (Elkington, 1998). Triple bottom line melalui triple $P$ menggambarkan aspek sosial (people), aspek lingkungan (planet), dan aspek ekonomi (profit). Konsep ini bertujuan untuk menyelaraskan hubungan antara manusia, lingkungan, dan ekonomi.

Sayangnya, ketiga aspek tersebut belum mampu menghadirkan satu nilai penting dalam akuntansi sosial-lingkungan, yakni aspek spiritualitas. Sukoharsono dalam pidoato pengukuhan guru besarnya pada tahun 2010 kemudian mencoba menyempurnakan enterprise theory yang dibangun oleh Elkington dengan menambahkan aspek spiritualitas. Suyudi (2012) kemudian menyebut ini dengan istilah Quadrangle Bottom Line. Hanya saja, konsep ini terlihat belum tepat dikarenakan, pada konsep ini, spiritualitas merupakan satu dimensi tambahan yang melengkapi tiga dimensi sebelumnya. Padahal, sejatinya spiritualitas akan melekat pada segala yang dikerjakan manusia, karena kinerja ekonomi, sosial, dan lingkungan tidak akan dapat dicapai apabila kinerja spiritual tidak tercapai (Slamet, 2001; Sukoharsono, 2010; Suyudi, 2012).

Berpijak dari permasalahan tersebut, tulisan ini mencoba untuk menyempurnakan konsep yang telah ada dengan menyusun kembali keterkaitan antara dimensi triple $P$ dan spiritualitas. Bila triple $p$ yang tidak lain merupakan pengukuran kinerja social-lingkungan perusahaan dikaitkan dengan spiritualitas, maka spiritualitas harusnya menjadi landasan dalam penentuan aspek-aspek yang perlu dinilai. Konsep yang kemudian dirasa tepat menjadi landasan ini adalah konsep Eco-Theology Islam.

Eco-theology merupakan bentuk teologi konstruktif yang menjelaskan hubungan agama dan alam (Quddus, 2012). Beberapa literatur yang ada menjelaskan bahwa konsep eco-theology ini berlandaskan pada prinsipprinsip kristen yang mengacu pada injil (Dalton \& Simmons, 2010; Jones, 2004). Selanjutnya, beberapa tahun terakhir artikel-artikel muslim mulai membahas konsep ini melalui perspektif Islam, dalam hal ini Al-Qur'an (Quddus, 2012; Iswanto, 2013). Konsep ini melahirkan tiga prinsip untuk membangun sebuah eco-theology yaitu tawhìd (kesatuan seluruh makhluk), amānah-khalīfah (kejujurankepemimpinan), dan ākhirah (tanggung jawab). Bila dihubungkan dengan spiritualitas, maka ketiga prinsip ini dirasa mampu 
menjadi basis dalam menentukan aspek-aspek yang perlu dilaporkan dalam laporan sustainabilitas. Dimana ketiganya memiliki dasar yang jelas yakni berpedoman pada Al-Qur'an.

Tulisan ini diharapkan dapat memberikan kontribusi berupa pemahaman baru terkait akuntansi sosial-lingkungan dalam kaitannya dengan spiritualitas. Selain itu, tulisan ini juga dapat menjadi pertimbangan bagi perusahaan khususnya yang berlandaskan syariah dalam penerapan akuntansi sosial-lingkungannya.

\section{HASIL DAN PEMBAHASAN}

\section{A. Akuntansi Sosial-Lingkungan Perspektif Spiritualitas}

Akuntansi Sosial atau yang dikenal sebagai akuntansi sosial dan lingkungan, pelaporan sosial perusahaan, atau pelaporan tanggung jawab sosial perusahaan adalah proses mengkomunikasikan dampak sosial dan lingkungan dari tindakan ekonomi organisasi untuk kepentingan kelompok tertentu dalam masyarakat dan masyarakat luas (Gray, Owen, \& Maunders, 1987). Crowther (2000) mendefinisikan akuntansi sosial dalam pengertian ini sebagai pendekatan untuk melaporkan aktivitas perusahaan yang menekankan perlunya identifikasi perilaku yang relevan secara sosial, penentuan mereka yang menjadi tanggungan perusahaan atas kinerja sosialnya dan pengembangan tindakan yang tepat dan teknik pelaporan. Sehingga Akuntansi sosial bisa dikatakan sebagai salah satu aspek yang menekankan gagasan akuntabilitas perusahaan.

Akuntansi sosial dalam penerapannya memiliki bebarapa tujuan. Setidaknya ada tiga tujuan akuntansi sosial menurut Ramanathan (1976). Tujuan pertama yakni melihat seberapa besar manfaat dan biaya serta kontribusi sosial yang dilakukan oleh perusahan dalam menjalankan tanggung jawab sosialnya, baik kepada masyarakat maupun lingkungan. Tujuan yang kedua yakni, melihat apakah prioritas sosial telah dilakukan secara maksimal, sehingga permasahan sosial yang timbul dari kegiatan bisnis perusahaan terselesaikan. Tujuan yang ketiga memberikan informasi yang relevan kepada kelompok ataupun masyarakat tentang tujuan, kebijakan dan kontribusi perusahaan terhadap aktivitas sosial.

Ketiga tujuan tersebut menjadi dasar kemunculan akuntansi sosiallingkungan ala Elkington yang lebih dikenal dengan istilah Triple $P$. Ini merupakan wujud kepedulian yang tidak hanya ditujukan kepada sesama manusia, namun juga kepada lingkungan. Tidak berhenti sampai disitu, para pemikir terus mengkaji aspek-aspek penting apa yang diperlukan dalam perbaikan akuntansi. Salah satu yang kemudian banyak mendapat perhatian adalah aspek spiritualitas.

Spiritualitas dapat dipahami bahwa setiap individu dan organisasi memiliki tanggungjawab membangun peristiwa-peristiwa ekonomi, sosial dan lingkungan dalam organisasinya yang direlasikan dengan holy spirit. Dimana holy spirit merupakan bentuk berbasis universalitas dan religiusitas. Holy spirit dalam bentuk universalitas dapat dimaknai dengan kasih yang tulus (merciful), cinta yang tulus (truthful love), kesadaran transcendental, mampu melakukan kontemplasi diri, dan kejujuran. Sukoharsono (2010) memandang lima dimensi ini merupakan indikator utama dalam proses pertanggungjawaban individu dan organisasi disekelilingnya. Meskipun, dimensi-dimensi ini merupakan sesuatu yang bersifat universal (umum), namun tetap saja dimensi-dimensi ini masih sulit diukur, karena tidak ada 
ukuran mutlak dan lebih berfikat relatif. Oleh sebab itu, dirasa pelu untuk meninjaunya dari sisi yang berbeda, yakni religiusitas.

Holy spirit dalam bentuk religutias dapat dimaknai sebagai tindakan yang berlandaskan pada nilai-nilai keagamaan. Tuhan telah mengatur setiap aspek kehidupan manusia, mulai dari bangun hingga tidur kembali semua sudah diatur dalam agama, termasuk kegiatan ekonomi. Bila kita melihat dari perspektif agama Islam, kegiatan ekonomi merupakan salah satu hal yang menjadi pokok perhatian dalam ajaran islam, sehingga ada begitu banyak ayat Al-Qur'an maupun hadits yang menjelaskan bagaimana semestinya umat muslim melakukan kegiatan ekonomi sesuai dengan syariat islam. Akuntansi yang merupakan bagian dari kegiatan ekonomi juga tidak lepas dari aturan islam. Bahkan didalam Al-Qur'an ayat terpanjang menjelasakan tentang akuntansi dari berbagai aspek.

Pada QS Az-Dzariyyat ayat 19, Allah berfirman:

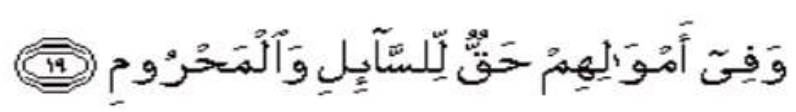

"Dan pada harta-harta mereka ada hak untuk orang miskin yang meminta dan orang miskin yang tidak mendapat bahagian."

Ayat ini menjelaskan bahwasanya didalam harta kita ada hak orang lain yang harus kita berikan. Hal ini bisa kita kaitkan dengan akuntansi sosial, bahwasanya dalam laba yang dimiliki perusahaan itu ada hak orang lain yang harus dipenuhi, ada kewajiban sosial yang harus diberikan perusahaan kepada masyarakat terutama masyarakat yang terkena dampak kegiatan bisnis perusahaannya. Secara luas, kewajiban sosial mencakup bantuan sosial berupa kebutuhan dasar hidup, jaminan sosial terhadap risiko, pemeliharaan publik dan sebagainya.

Selain itu, dalam QS Al-Baqarah ayat 2015 juga terkandung makna bahwa akuntansi sosial harus memperhatikan prioritas yang harus didahulukan dalam melakukan tanggung jawab sosial. Menurut ketentuan syariah skala prioritas yang harus dipenuhi dalam akuntansi sosial adalah kepada ibu-bapak, kaum kerabat, anak-anak yatim, orangorang miskin dan orang-orang yang sedang dalam perjalanan.

\section{B. Konsep Circle Bottom Line}

Dalam perjalanannya, akuntansi sosial dan lingkungan mendapatkan banyak respon dari para pemikir sehingga dapat terus mengalami perbaikan. Ini juga merupakan wujud kepedulian yang tidak hanya ditujukan kepada sesama manusia, namun juga kepada lingkungan. Namun, seiring perkembangan ilmu pengetahuan, enterprise theory yang merupakan landasan dalam pelaksanaan akuntansi sosial-lingkungan mulai mendapat kritikan dari beberapa pihak. Salah satunya adalah penelitian yang dilakukan oleh Suyudi (2012) yang kemudian memberikan informasi bahwa dimensi spirtiual merupakan dimensi penting dalam akuntansi sosial-lingkungan. Ini yang kemudian melahirkan konsep quadrangle bottom line yang mencakup empat dimensi; ekonomi (profit), sosial (people), lingkungan (planet), spiritualitas.

Dimensi ekonomi mempunyai misi penting untuk direvitalisasi agar pertumbuhan ekonomi dapat memerangi kemiskinan dan pengangguran. Dimensi sosial dan lingkungan memiliki misi agar dimensi ekonomi tidak mengeksploitasi alam secara membabi-buta hanya untuk kepentingannya. Dapat dikatakan bahwa, dimensi ini adalah penetral peristiwaperistiwa 
ekonomi yang akan dan telah dilakukan sebagai wujud kepedulian terhadap modal dasar ekonomi dalam menggerakan organisasi bisnis. Sedangkan, dimensi spiritual memiliki misi penyeimbang makna kehidupan terhadap diri, antar individu dan kelompok organisasi.

Berangkat dari makna filosofis atas istilah quadrangle bottom line, quadrangle merupakan bentuk yang memiliki empat sisi yang kemudian melambangkan empat dimensi akuntansi sosial-spiritual. Keempat sisi ini harus memiliki porsi yang sama agar membentuk persegi yang sempurna. Namun bila kita telaah lebih jauh mengenai konsep ini, keempat dimensi ini memiliki kedudukan dan peran yang sama. Ini menandakan adanya keterpisahan antara dimensi spiritual dengan tiga aspek lainnya. Hal ini sedikit berbenturan dengan penyataan yang dikemukakan oleh Suyudi (2012) bahwa kinerja ekonomi, sosial dan lingkungan tidak akan dapat dicapai apabila kinerja spiritual tidak tercapai. Pernyataan ini melambangkan bahwa spiritualitas berperan sebagai dimensi pendukung dari ketiga aspek tersebut.

Selain itu, bila dikaitkan dengan konsep triple bottom ala Elkington, maka konsep ini menjadi lebih membingungkan. Dimana, pada triple bottom line, ketiga dimensi tersebut merupakan aspek-aspek pertanggungjawaban perusahaan. Dengan kata lain, perusahaan memiliki tanggungjwab ekonomi, sosial, dan lingkungan. Kemudian, penambahan aspek spirirtualitas sebagai dimensi pelengkap berarti juga memandang bahwa perusahaan memiliki tanggungjawab spiritualitas. Padahal, sejatinya spiritualitas merupakan hal yang berasal dari hati, yang melandasi setiap perbuatan baik manusia. Sehingga, memandagnya sebagai dimensi pertanggungjawaban merupakan hal yang kurang tepat.

Berdasarkan telaah di atas, dapat dibentuk satu konsep baru yang tidak menyamakan kedudukan dimensi spiritualitas dengan ketiga dimensi yang lain, yakni dalam bentuk circle bottom line. Untuk memperjelas, berikut ilustrasi konsep quadrangle bottom line dan circle bottom line.
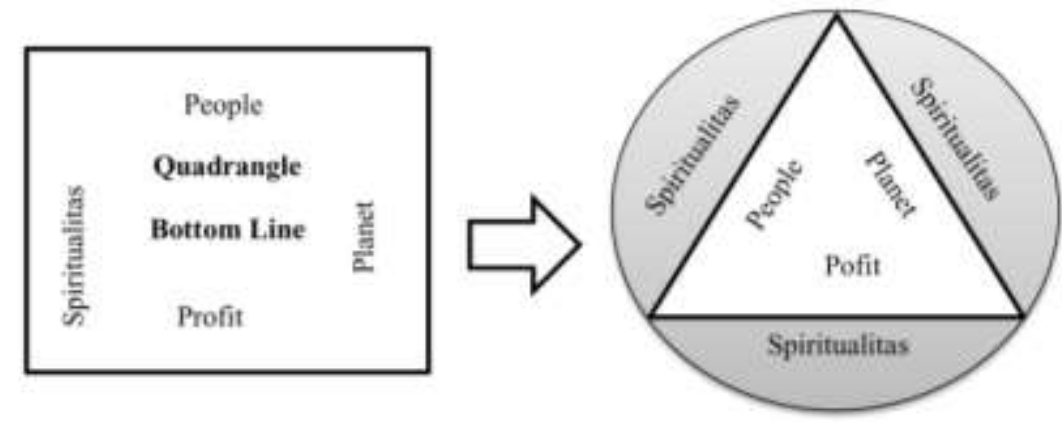

Gambar 1. Quadrangle Bottom Line dan Circle Bottom Line Gambar

Gambar 1 memperlihatkan bahwa, berbeda dengan quardrangle bottom line yang menyamakan kedudukan dimensi spiritualitas dengan dimensi yang lain, pada konsep circle bottom line, dimensi spiritualitas melingkupi setiap dimensi triple bottom line. Ini dikarenakan, spiritualitas bukanlah suatu hal yang perlu pertanggungjwabkan nantinya, namun justru menjadi basis dalam pelaksanaan akuntansi sosial-lingkungan.

Setiap kegiatan harus didasari dengan spiritualitas. Selain itu, spiritualitas juga berperan sebagai penyempurna. Bentuk triple bottom line yang sebelumnya berbentuk segitiga, melalui sentuhan spiritualitas bentuknya berubah menjadi circle (lingkaran). Secara filosofis, bentuk circle (lingkaran) melambangkan keutuhan sinergi, dimana tidak ada lagi segi-segi yang membatasi korelasi antara satu sisi dengan sisi yang lain. Tidak hanya 
itu, circle (lingkaran) yang tidak memiliki sudut juga melambangkan perputaran sempurna, dengan kata lain dengan melibatkan dimensi spiritualitas pada akuntansi sosial-lingungan, diharapkan pertanggungjawaban dan perbaikan berkelanjutan akan terus terjadi.

Perubahan bentuk relasi quadrangel menjadi circle, tidak hanya merubah makna filosofisnya saja, namun juga misi masing-masing dimensinya yaiyu: 1) Dimensi Sosial (People). Dimensi ini mengasumsika bahwa keberlangsungan usaha selalu terikat dan terkait dengan sosial kemasyarakatan. Ada 4 (empat) indikator dalam melaporkan aktivitas sosial tersebut yaitu praktek ketenagakerjaan dan kelayakan kerja, Hak Asasi Manuasi (HAM), masyarakat, tanggungjawab produk/Jasa. Semua ini harus sesusai dengan rambu-rambu agama; 2) Dimensi Lingkungan (Planet). Maksud dari dimensi ini adalah aktivitas organisasi selalu memanfaatkan lingkungan dalam beroperasi. Namun, pemanfaaan lingkungan dalam hal ini tentu sesuai dengan ketentuan agama Islam karena telah dilingkupi dengan dimensi spiritualitas; 3) Dimensi Ekonomi (Profit). Dimensi ini melaporkan aktivitas organisasi tentang relasi yang terjadi dan terkait dengan kebijakan manajemen secara menyeluruh yang berlandaskan pada spiritualitas. Dimensi Ekonomi terdiri dari aspek ekonomi langsung dan ekonomi tidak langsung; 4) Dimensi Spiritualitas. Pada circle bottom line, dimensi ini tidak lagi berdiri sendiri. Namun melingkupi setiap dimensi lainnya melalui nilainilai keagamaan. Dalam hal ini, konsep Eco-Theology Islam.

\section{Akuntansi Sosial-Lingkungan Berdimensi Eco-Theology Islam}

Tanggung jawab manajemen tidak hanya sebatas pada economic bottom line saja, namun lebih luas pada pengelolaan dampak yang ditimbulkan atas lingkungan, sosial dan ekonomi. Meskipun laporan pertanggungjawaban sosial-lingkungan perusahaan bersifat sukarela, namun ini juga telah menjadi tuntutan stakeholder agar entitas memiliki tanggung jawab sosial dan lingkungan(Suartana, 2010; Suaryana, 2011; Williams, 1999). Ini yang kemudian membuat kajian tentang akuntansi sosial-lingkungan masih terus berkembang hingga saat ini.

Salah satu kajian yang menarik adalah terkait spiritualitas. Keterkaitan antara akuntansi sosial-ingkungan dengan spiritualitas dipandang penting karena kinerja ekonomi, sosial dan lingkungan tidak akan dapat dicapai apabila kinerja spiritual tidak tercapai. Dalam hal ini, spiritualitas yang dimaksud merupakan aspek religiusitas khususnya ditinjau dari nilai-nilai agama Islam.

Spirit religius dalam agama Islam tentu sangat beragam. Salah satu yang tepat untuk menjadi basis adalah konsep Eco-Theology Islam. Quddus (2012) memberikan tiga prinsip terkait Eco-Theology Islam, yakni; tawhìd (kesatuan seluruh makhluk), amānah-khalifah (kejujuran-kepemimpinan), dan âkhirah (tanggung jawab).

Tawhīd (Kesatuan Seluruh Makhluk). Menurut Nasr (2003), Tawhīd merupakan jantung agama Islam (the heart of Islamic life). Dan hidup yang bermanfaat adalah hidup yang mampu merealisasikan makna prinsip Tawhì ke dalam realitas hidup, yaitu meraih dan menyatukan berbagai keragaman (mutiplecity) dalam bingkai kesatuan (unity). Cara pandang yang berbasis tawhīd melihat segala sesuatu dalam alam ini bersumber dari Allah dan akan kembali kepada Allah, bahkan semuanya mengelilingi Allah. Dalam kaitannya dengan dimensi triple bottom line, maka ini dapat menjadi basis pengukuran dimensi lingkungan (planet). Dimana, tawhid harus menjadi nilai dasar 
manusia dalam memahami alam. Alam harus dilihat sebagai ayat atau simbol yang dapat mengantarkan manusia agar sampai pada realitas sejati. Meski alam diciptakan untuk manusia, namun hak yang dimiliki manusia hanya terbatas pada hak pemanfaatan yang nantinya akan diminta pertanggungjawabannya. Manusia hanya memperoleh hak pakai, bukan hak milik. Untuk itu, manusia harus selalu menjaga eksistensi apa-apa yang telah Allah berikan di alam ini. Misalnya, sumber daya alam, manusia berhak memanfaatkannya, namun juga perlu menjaga kelangsungannya. Ini merupakan konsep keberlajutan yang dapat diterpakan dalam akuntansi sosial-lingkungan yang berbasis Eco-Theology Islam.

\section{Amānah-Khalīfah (Kejujuran-Kepemimpinan). Sejak awal} penciptaannya, manusia telah menerima Amānah dari Allah untuk menjadi Khalifah di muka bumi ini (QS al-Ahzab: 72). Dalam konteks akuntansi sosial lingkungan, amānah-khaliffah dapat dikaitkan dengan dimensi sosial (people). Keterwakilan dimensi ini terwujud melalui prinsip amānah-khalïfah yang dimaksudkan bahwa dalam melaksanakan praktik bisnis, hubungan sosial harus dipelihara dengan baik. Tidak hanya dengan pihak atas (pimpinan dan pemilik perusahaan) namun juga pihak bawah (karyawan) dan masyarakat. Dan semua pekerjaan yang diemban harus dilaksanakan dengan sebaikbaiknya sesuai prinsip amānah.

Ākhirah: sebuah model akuntabilitas dan konsekuensi. Ini merupakan prinsip yang menjelaskan tentang keberadaan akhirat. Keyakinan akan adanya hari pembalasan menunculkan persepsi bahwa segala perbuatan di dunia ini mempunyai konsekuensi di akhirat. Konsep ini dapat menjadi acuan dalam pembentukan etika. Bila dikatikan dengan laporan sustainabilitas-spiritualitas, maka ini dapat menjadi basis pengukuran dimensi ekonomi (profit). Dimana basis ini dapat menghindari adanya kecurangan terkait dengan ekonomi (fraud). Serta memungkin pelaksanaan bisnis yang sehat dan saling menguntungkan.

Dari ketiga aspek ini yang kemudian akan membingkai tiga dimensi triple bottom line. Hal ini dimaksudkan agar setiap tindakan yang dilaksanakan oleh perusahaan merupakan hal-hal yang diridhai oleh Allah SWT, sehingga penerapan akuntansi sosial-lingkungan tidak hanya untuk menggunggurkan tanganggung jawab dan memenuhi tuntutan stakeholder, melainkan juga untuk memeroleh rahmat-Nya.

\section{SIMPULAN}

Circle bottom line adalah penyempurnaan relasi dari konsep quadrangle bottom line. Secara filosofis, bentuk circle (lingkaran) melambangkan keutuhan sinergi, dimana tidak ada lagi segi-segi yang membatasi korelasi antara satu sisi dengan sisi yang lain. Tidak hanya itu, circle (lingkaran) yang tidak memiliki sudut juga melambangkan perputaran sempurna, dengan kata lain dengan melibatkan dimensi spirirtualitas pada akuntansi sosiallingungan, diharapkan pertanggungjawaban dan perbaikan berkelanjutan akan terus terjadi.

Konsep ini mencakup tiga dimensi yakni people (sosial), planet (lingkungan), profit (ekonomi) yang dilandasi dimensi spiritualitas dalam pengukurannya. Dimensi spiritualitas yang digunakan yakni spirit religius. Dalam hal ini adalah konsep Eco-Theology Islam yang berupa tiga prinsip, yakni; tawhìd (kesatuan seluruh makhluk), amānah-khalīfah (kejujurankepemimpinan), dan ākhirah (tanggung jawab). 
Relasi antar dimensi circle bottom line yang berbasis prinsip-prinsip Islam pada Eco-Theology Islam kemudian dijadikan sebagai dasar dalam penerapan akuntansi social-lingkungan

\section{DAFTAR PUSTAKA}

Al-Qur'an. (2015). Departemen Agama Republik Indonesia. Jakarta: Dharma Art.

Bebbington, J., Brown, J., Frame, B., \& Thomson, I. (2007). Theorizing Engagement: The Potential of a Critical Dialogic Approach. Accounting, Auditing and Accountability Journal. https://doi.org/10.1108/09513570710748544

Crowther, D. (2000). Social and Environmental Accounting. London: Financial Times Prentice Hall.

Dalton, A. ., \& Simmons, H. . (2010). Ecotheology and The Pactice of Hope. New York: State University of New York Press, Albany.

Elkington, J. (1998). Accounting for the Triple Bottom Line. Measuring Business Excellence. https://doi.org/10.1108/eb025539

Gray, R., Owen, D., \& Adams, C. (1996). Accounting \& Accountability: Changes and Challenges in Corporate Social and Environmental Reporting. Hemel Hempstead: Prentice Hall.

Gray, R., Owen, D., \& Maunders, K. . (1987). Corporate Social Reporting: Accounting and Accountability. Hemel Hempstead: Prentice Hall.

Jones, G. (2004). The Blackwell Companion to Modern Theology. In The Blackwell Companion to Modern Theology. https: / / doi.org/10.1002/9780470996768

Nasr, S. H. (2003). Islam; Religion, History, and Civilazation. USA Harpercollins Book.

Quddus, A. (2012). Ecotheology Islam: Teologi Konstruktif Atasi Krisis Lingkungan. Ulumuna, 16(2). https://doi.org/10.20414/ujis.v16i2.181

Ramanathan, K. V. (1976). Toward a Theory of Corporate Social Accounting. Source: The Accounting Review.

Slamet, M. (2001). Enterprise Theory dalam Konstruksi Akuntansi Syariah (Studi Teoritis pada Konsep Akuntansi Syari'ah). Unviversitas Brawijaya.

Suartana, I. W. (2010). Akuntansi Lingkungan dan Triple Bottom Line Accounting : Paradigma Baru Akuntansi Bernilai Tambah. Jurnal Bumi Lestari.

Suaryana, A. (2011). Implementasi Akunatnsi Sosial dan Lingkungan di Indonesia. Jurnal Ilmiah Akuntansi Dan Bisnis, 6(1).

Sukoharsono, E. G. (2010). Metamorfosis Akuntansi Sosial Dan Lingkungan: Mengkonstruksi Akuntansi Sustainabilitas Berdimensi Spiritualitas. Malang: Universitas Brawijaya.

Suyudi, M. (2012). Quardrangle Bottom Line (QBL) dalam Praktik Sustainability Reporting Dimensi "Spiritual Performance." Jurnal Akuntansi Multiparadigma, 3(1). https://doi.org/10.18202/jamal.2012.04.7148

Williams, S. M. (1999). Voluntary Environmental and Social Accounting Disclosure Practices in the Asia-Pacific Region: An International Empirical Test of Political Economy Theory. CFA Digest. https://doi.org/10.2469/dig.v30.n2.655 